Original Article

\title{
An effective strategy to reduce blood pressure after forest walking in middle-aged and aged people
}

\author{
Masahiro Horiuchi ${ }^{1)^{*}}$, Junko Endo ${ }^{1)}$, Shin Akatsuka ${ }^{1)}$, Tatsuya Hasegawa ${ }^{1)}$, \\ ERIKo Yamamoto ${ }^{1)}$, TAdashi $\mathrm{UnO}^{1)}$, Sachiko KikUChI ${ }^{1)}$ \\ 1) Division of Human Environmental Science, Mt. Fuji Research Institute: 5597-1 Kamiyoshida, \\ Fujiyoshida city, Yamanashi 403-0005, Japan
}

\begin{abstract}
Purpose] Forest walking may be effective for human health, but little information is available about effects of energy expenditure on blood pressure responses after forest walking. The aim of this study was to investigate the relationship between the activity energy expenditure and changes in blood pressure in individuals after forest walking. [Subjects] The subjects were 54 middle-aged and elderly people. [Methods] All subjects walked in the forest for approximately $90 \mathrm{~min}$. Blood pressure, salivary amylase, and the Profile of Mood States were evaluated before and after forest walking, and activity energy expenditure was monitored throughout forest walking. Subjects were divided into two groups according to mean arterial pressure changes: a responder group ( $>5 \%$ decreases) and a nonresponder group $(<5 \%)$. [Results] Forest walking significantly reduced the mean arterial pressure and improved the Profile of Mood States in both groups. Activity energy expenditure was related to changes in mean arterial pressure in the responder group, while this relation was not observed in the nonresponder group. Differential activity energy expenditure did not strongly affect improvement of the Profile of Mood States. [Conclusion] Greater walking-related greater activity energy expenditure might be required to accentuate physiological beneficial effects on in middle-aged and aged people. Furthermore, the forest environment per se can attenuate psychological stress. Key words: Hypertension, Profile of Mood States, Responder and nonresponder
\end{abstract}

(This article was submitted Aug. 4, 2015, and was accepted Sep. 2, 2015)

\section{INTRODUCTION}

In Japan, "forest bathing"/“forest therapy", which is known as "shinrin-yoku", has received widespread attention as a novel form of therapy. Indeed, numerous studies examining the effects of forest environments, including bathing and walking in forest environments, on psychological states, such as emotions and $\operatorname{mood}^{1-4)}$, and on physiological factors, such as pulse rate and blood pressure (BP) ${ }^{1-4)}$, and salivary amylase (sAMY) activity ${ }^{5}$ have shown positive outcomes. From the viewpoint of clinical implications, one of these positive effects, that is, reductions of BP, may be particularly relevant for hypertensive patients and/or elderly people who generally have higher BPs, since hypertension is a major risk factor for cardiovascular diseases and is also associated with the urban environment ${ }^{6}$. Horiuchi et al. ${ }^{7)}$ recently investigated the effects of forest walking on BP and other variables in young and elderly people, and reported a reduction of BP in both groups. Furthermore, they also reported that the effects were greater in elderly people, suggesting that forest walking may be a useful strategy for improving quality of

*Corresponding author. Masahiro Horiuchi (E-mail: mhoriuchi@mfri.pref.yamanashi.jp)

(C)2015 The Society of Physical Therapy Science. Published by IPEC Inc. This is an open-access article distributed under the terms of the Creative Commons Attribution Non-Commercial No Derivatives (by-ncnd) License $<$ http://creativecommons.org/licenses/by-nc-nd/3.0/> . life in this population ${ }^{7)}$. However, a limitation of their study was that its protocol could not rule out the influence of exercise per se, that is, walking, meaning that there is a lack of discrimination between the effect of forest environments and the effect of exercise walking. Thus, it remains unclear which, the forest environment or exercise walking, has the predominant influence in reducing BP.

Previous studies demonstrated that a greater magnitude and longer duration of postexercise hypotension (PEH) was observed after a higher exercise intensity ${ }^{8-10)}$ and/or longer exercise $^{9)}$, suggesting that enhanced energy expenditure (EE) elicits a greater reduction in BP. In addition, a previous study demonstrated that a single bout of aerobic exercise caused $24 \mathrm{~h}$ BP reductions in middle-aged and aged people with type 2 diabetes and prehypertension, and this reduction may depend on a higher exercise intensity ${ }^{11)}$. Although "forest walking" is carried out at a slower and self-regulated pace, it is possible that EE may be related to changes in the BP of individuals. Unfortunately, it remains unclear whether greater EE can produce a greater reduction in BP during forest walking. Therefore, it is necessary to clarify a better way to reduce BP after forest walking, because "forest bathing"/ "forest therapy" has been reported as a novel form of therapy ${ }^{1-4)}$.

In this study, we hypothesized that greater EE would lead to a greater reduction in BP following forest walking in middle-aged and elderly people. To test this hypothesis, we used a uniaxial accelerometer to monitor EE, because the device is easy to use and its validity and reliability have 
been confirmed in a previous study ${ }^{12}$. As secondary evaluations, we also measured sAMY and the Profile of Mood States (POMS), which have been used to assess the impact of forest walking in previous studies ${ }^{1-4)}$.

\section{SUBJECTS AND METHODS}

Fifty-four volunteers (19 males and 35 females) with a mean age of $63.2 \pm 9.4$ years (mean $\pm \mathrm{SD}$ ) were recruited from Kofu City, and the surrounding community using flyers and the web-page of Yamanashi Prefecture. Some participants were taking medications for hypertension, diabetes, hyperlipidemia, hyperuricemia, and osteoporosis. In addition, the menstrual cycle was surveyed for females on an individual basis. This study was performed on 4 different days, and each participant took part on 1 day. After receiving a detailed description and explanation of the study procedures and the possible risks and benefits of participation, each participant signed an informed consent form. All participants were nonsmokers, and they were asked to abstain from consuming caffeinated beverages for $12 \mathrm{~h}$ and to refrain from engaging in strenuous exercise or consuming alcohol for a minimum of $24 \mathrm{~h}$ before the experiment. All procedures used in the present study were approved by the ethics committee of the Mt. Fuji Research Institute and were performed in accordance with the guidelines of the Declaration of Helsinki.

The subjects visited an administrative office of "Takedano-mori," which was newly registered as a forest therapy home base in Japan in 2014, at 9:00 AM each day, and all studies ended at 12:00 PM. This site is located in Kofu City, Yamanashi Prefecture, which is approximately $100 \mathrm{~km}$ west of Tokyo. First, the body weight, including clothes, baggage, and shoes, of the participant was measured to calculate energy expenditure. Each individual's BP variables, sAMY, and POMS scores were evaluated before and after forest walking. During the pre-forest-walking measurements, each participant sat on a chair in an upright position for $20 \mathrm{~min}$ and then completed the POMS questionnaire, which took for about $10 \mathrm{~min}$. Their saliva was then collected, and BP was measured with the participant still in this position. Thus saliva collection and BP measurement were performed after 30 min of resting in a sitting position. The framework of the forest walking was as follows: 1) 5 min slow walking, 2) 5 min stretching, 3) 25-30 min self-paced comfortable walking, 4) $20 \mathrm{~min}$ forest viewing in a supine position, and 5) 30-35 min self-paced comfortable walking. Thus, the total time was about $90 \mathrm{~min}$. Post-forest-walking measurements were also obtained. Briefly, after a $10 \mathrm{~min}$ recovery period in a sitting position, each subject again completed the POMS questionnaire in the same manner as before forest walking. Their saliva was then collected, and BP was measured with the participant still in this position. Thus both measurements were carried out after a 20 min recovery period in a sitting position.

Systolic and diastolic BP (SBP and DBP) values were measured by an oscillometric method using a digital BP monitor (HEM-7420, Omron, Tokyo, Japan) using the upper left arm of each participant while they sat on a chair. BP was measured at least twice, with a 30 -s interval between replicates, both before and after forest-walking. If the differ- ence between the measurements of either SBP or DBP was $>5 \mathrm{mmHg}$, the measurements were repeated. The average $\mathrm{BP}$ values of pairs of measurements were taken as the BP values, excluding those that were $>5 \mathrm{mmHg}$ values.

The sAMY concentration, which was previously established as a marker of stress $\left.{ }^{13}, 14\right)$, was measured using a handheld sAMY monitor (CM-2.1, Nipro Corporation, Osaka, Japan). Since it has been reported that increased sympathetic nerve activity is a major stimulator of amylase secretion, increases in SAMY were considered to indicate enhanced stress $^{5,14)}$. The abovementioned handheld monitor consists of a disposable test strip and an optical analyzer that contains an automatic saliva transcription device. A volume of about $30 \mu \mathrm{L}$ of saliva was collected by the collection paper, which was placed under the tongue of the participant. The time allocated to saliva collection was $30 \mathrm{~s}$ for each participant, and it took $30 \mathrm{~s}$ to transfer and analyze the saliva using the handheld monitor. The validity of this device for measurement of sAMY has been confirmed in a previous study ${ }^{14)}$.

EE was measured using a commercial activity monitor based on a uniaxial accelerometry sensor (Lifecorder EX or Lifecorder GS, Suzuken Co., Ltd., Nagoya, Japan). Due to a number of device limitations, we used two kinds of activity monitor; however, according to the technical details provided by the manufacturer (Suzuken Co., Ltd.), these devices use exactly the same principles for measurement of EE. The validity of these devices for assessment of EE using a unique algorithm has been confirmed in a previous study ${ }^{12)}$. Briefly, when the sensor detects three acceleration pulses or more for 4 consecutive s, activity EE (AEE) is calculated and recorded every 4 seconds using the individual's body weight. The AEE data can then be downloaded using special software via a personal computer.

The POMS is a well-established, factor-based, analytically derived measure of psychological distress, and its reliability and validity have been well documented ${ }^{15}$. It measures six mood states: tension and anxiety (T-A), depression (D), anger and hostility (A-H), vigor (V), fatigue (F), and confusion (C). The short Japanese version of the POMS, which covers 30 items $^{16}$ ), was used, and its raw score was used for our statistical analysis.

Responders were classified as those participants who showed a reduction in mean arterial pressure (MAP) of $>$ $5 \%$ between before and after forest walking. MAP was used in the classification of responders (Rs) and nonresponders (NRs) as it fully represents the perfusion pressure observed in organs. The percentage of responses ( $\%$ response) in MAP was calculated using the following equation: (post-forestwalking MAP- pre-forest-walking MAP $) \times(100 /$ pre-forestwalking MAP). Table 1 shows the physical characteristics, current medications, and menstrual cycle details of the $\mathrm{R}$ and NR groups.

MAP was calculated as $[(\mathrm{SBP}-\mathrm{DBP}) / 3+\mathrm{DBP}]$. Due to greater variability of the sAMY values between and within the participants, logarithmic transformation was carried out, and the data for sAMY were presented as a natural logarithm $(\log \mathrm{e})$.

The data are expressed as mean values \pm the standard error of the mean (SEM). An unpaired t test was used to compare the physical characteristics between the two groups. A 
$\chi^{2}$ test was also conducted to compare gender variability, medication status, menstrual cycle, number of participants in each group on the 4 different days, and classification of BP. A two-way repeated analysis of variance (ANOVA) was used to compare physiological and psychological responses (SigmaStat ver. 3.5, Hulinks, Chicago, IL, USA), and a Bonferroni post hoc test was employed. A Pearson correlation coefficient between percentage (\%) changes in MAP and AEE during forest walking was obtained, and a p-value of $<0.05$ was considered statistically significant.

\section{RESULTS}

Physical characteristics were similar between groups, while, \% change in MAP was significantly greater in Rs than in NRs (Table 1). The $\chi^{2}$ test revealed no significant differences in gender $\left(\chi^{2}(1)=0.325, \mathrm{p}=0.569\right)$, medica-

Table 1. Physical characteristics, medications and menstrual cycle statuses of the responder and nonresponder groups

\begin{tabular}{|c|c|c|}
\hline & Responder & Nonresponder \\
\hline Gender (males/females, n) & $11 / 16$ & $8 / 19$ \\
\hline Age (years) & $63.9 \pm 1.6$ & $61.6 \pm 2.1$ \\
\hline Height $(\mathrm{cm})$ & $159.3 \pm 1.6$ & $159.2 \pm 1.4$ \\
\hline Body weight (kg) & $64.8 \pm 2.4$ & $61.0 \pm 1.6$ \\
\hline Body mass index $\left(\mathrm{kg} \mathrm{m}^{2}\right)$ & $25.4 \pm 0.7$ & $24.1 \pm 0.5$ \\
\hline $\begin{array}{l}\text { Response of mean arterial } \\
\text { pressure }(\%)\end{array}$ & $-9.9 \pm 0.8^{*}$ & $-1.7 \pm 0.4$ \\
\hline \multicolumn{3}{|l|}{ Medications (n) } \\
\hline Hypertension & 6 & 5 \\
\hline Diabetes & 2 & 4 \\
\hline Hyperuricemia & 3 & 2 \\
\hline Hyperlipidemia & 4 & 3 \\
\hline Osteoporosis & 2 & 2 \\
\hline \multicolumn{3}{|l|}{ Menstrual cycle (n) } \\
\hline Menstrual period & 1 & 0 \\
\hline Follicular phase & 1 & 1 \\
\hline Ovulation period & 0 & 1 \\
\hline Luteal phase & 0 & 1 \\
\hline Menopause & 14 & 16 \\
\hline Hormone replace treatment & 0 & 0 \\
\hline
\end{tabular}

Values are shown as the mean \pm standard error of the mean (SEM). ${ }^{*} \mathrm{p}<0.05$ vs. nonresponder group tion $\left(\chi^{2}(4)=1.071, \mathrm{p}=0.899\right)$, and menstrual cycle status $\left(\chi^{2}(4)=2.897, \mathrm{p}=0.575\right)$. Classification of BP according to the Guidelines for the Management of Hypertension in Japan $^{17)}$, is shown for the two groups in Table 2. Approximately $60 \%$ of the participants in each group were classifies as prehypertensive and hypertensive. The $\chi^{2}$ test showed no significant difference in BP classifications between the two groups $\left(\chi^{2}(5)=7.993, \mathrm{p}=0.157\right)$.

A comparison of physiological variables between the two groups for before and after forest walking, established pre and post forest-walking, is shown in Table 3. No significant differences were observed in pre-forest-walking values of SBP and MAP between groups ( $p>0.05$, respectively), and after forest walking, both $\mathrm{BP}$ variables were significantly decreased ( $p<0.05$ respectively). In contrast, pre-forestwalking DBP values were significantly higher in the R group compared with the NR group $(\mathrm{p}=0.027)$; moreover, they significantly decreased only in Rs $(p<0.001)$, while they remained unchanged in NRs $(\mathrm{p}=0.984)$. Two-way repeated ANOVA failed to find significant differences in sAMY changes with logarithmic transformation between the two groups $(\mathrm{p}>0.05)$. The AEE in the $\mathrm{R}$ group during forest walking was significantly greater compared to with that of the NR group ( $142 \pm 6$ vs. $117 \pm 5 \mathrm{kcal}, \mathrm{p}=0.001)$.

Table 4 shows changes in the subscales of the POMS between the two groups. There were no significant differences between groups in the pre-forest-walking values of the subscales of the POMS ( $>00.05$, respectively), with the exception of A-H $(p<0.05)$. Forest walking significantly improved the subscales of the POMS in both groups $(\mathrm{p}<0.05$, respectively), with no statistical differences between the two groups ( $p>0.05$, respectively). Only the A-H subscale of the POMS in the NR group did not improve after forest walking $(\mathrm{p}>0.05)$.

AEE was correlated with MAP changes in Rs ( $F$ [1, $25]=9.858, \mathrm{r}=0.532, \mathrm{p}=0.004, \mathrm{n}=27)$, but this was not observed in NRs $(F[1,25]=1.311, r=0.223, p=0.263, n=27)$.

\section{DISCUSSION}

The major findings of the present study were that forest walking may have a health benefit that reduces MAP and improves the subscales of the POMS in middle-aged and elderly people. In addition, enhanced AEE during forest walking was associated with changes in MAP, but enhanced AEE did not affect the POMS. Collectively, these results

Table 2. Classification of blood pressure (BP) values in the two groups, according to the Japanese Society of Hypertension

\begin{tabular}{llcc}
\hline & & Responder (n) & Nonresponder (n) \\
\hline Optimum BP & $\mathrm{SBP}<120$ and DBP $<80$ & 5 & 8 \\
Normal BP & $\mathrm{SBP}<130$ and DBP $<85$ & 6 & 2 \\
Prehypertension & SBP 130-139 or DBP 85-89 & 1 & 6 \\
Hypertension I & SBP $140-159$ or DBP 90-99 & 10 & 7 \\
Hypertension II & SBP $160-179$ or DBP 90-99 & 2 & 3 \\
Hypertension III & SBP $\geq 180$ or DBP $\geq 110$ & 3 & 1 \\
\hline
\end{tabular}

SBP: systolic BP; DBP: diastolic BP 
Table 3. Comparison of the BP variables and salivary amylase before (pre) and after (post) forest walking between the two groups

\begin{tabular}{|c|c|c|c|c|c|c|c|c|c|c|}
\hline & \multicolumn{2}{|c|}{ Responder } & \multicolumn{2}{|c|}{ Nonresponder } & \multicolumn{6}{|c|}{ Two-way ANOVA F and $\mathrm{p}$ values $(\mathrm{df}=1,52)$} \\
\hline & \multirow[t]{2}{*}{ Pre } & \multirow[t]{2}{*}{ Post } & \multirow[t]{2}{*}{ Pre } & \multirow[t]{2}{*}{ Post } & \multicolumn{2}{|c|}{ Group } & \multicolumn{2}{|c|}{ Time } & \multicolumn{2}{|c|}{ Interaction } \\
\hline & & & & & $\mathrm{F}$ & $\mathrm{p}$ & $\mathrm{F}$ & $\mathrm{p}$ & $\mathrm{F}$ & $\mathrm{p}$ \\
\hline $\mathrm{SBP}(\mathrm{mmHg})$ & $141 \pm 4$ & $125 \pm 4 *$ & $134 \pm 4$ & $127 \pm 4^{*}$ & 0.169 & 0.686 & 117.098 & $<0.001$ & 19.339 & $<0.001$ \\
\hline $\mathrm{DBP}(\mathrm{mmHg})$ & $83 \pm 2$ & $76 \pm 2 *$ & $77 \pm 2$ & $77 \pm 2$ & 1.052 & 0.310 & 32.600 & $<0.001$ & 32.928 & $<0.001$ \\
\hline MAP (mmHg) & $103 \pm 3$ & $92 \pm 3 *$ & $96 \pm 2$ & $94 \pm 2^{*}$ & 0.582 & 0.449 & 129.792 & $<0.001$ & 53.939 & $<0.001$ \\
\hline Log e (sAmy) & $3.42 \pm 0.22$ & $3.15 \pm 0.21$ & $3.04 \pm 0.22$ & $3.27 \pm 0.23$ & 0.249 & 0.620 & 0.022 & 0.884 & 2.772 & 0.102 \\
\hline
\end{tabular}

Values are shown as the mean \pm SEM. MAP: mean arterial pressure; sAmy: salivary amylase. ${ }^{*} \mathrm{p}<0.05$ vs. pre-forest-walking values within each group. ${ }^{*} \mathrm{p}<0.05$ vs. nonresponder group within pre-forest-walking values

Table 4. Comparison of the subscales of the Profile of Mood States before (pre) and after (post) forest walking between the two groups

\begin{tabular}{|c|c|c|c|c|c|c|c|c|c|c|}
\hline & \multicolumn{2}{|c|}{ Responder } & \multicolumn{2}{|c|}{ Nonresponder } & \multicolumn{6}{|c|}{ Two-way ANOVA $F$ and $p$ values $(\mathrm{df}=1,52)$} \\
\hline & \multirow[t]{2}{*}{ Pre } & \multirow[t]{2}{*}{ Post } & \multirow[t]{2}{*}{ Pre } & \multirow[t]{2}{*}{ Post } & \multicolumn{2}{|c|}{ Group } & \multicolumn{2}{|c|}{ Time } & \multicolumn{2}{|c|}{ Interaction } \\
\hline & & & & & $\mathrm{F}$ & $\mathrm{p}$ & $\mathrm{F}$ & $\mathrm{p}$ & $\mathrm{F}$ & $\mathrm{p}$ \\
\hline Tension-anxiety & $3.5 \pm 0.6$ & $0.7 \pm 0.2^{*}$ & $3.4 \pm 0.5$ & $0.6 \pm 0.3^{*}$ & 0.014 & 0.908 & 60.684 & $<0.001$ & 0.003 & 0.960 \\
\hline Depression & $1.9 \pm 0.5$ & $0.4 \pm 0.2^{*}$ & $1.3 \pm 0.4$ & $0.5 \pm 0.2^{*}$ & 0.657 & 0.421 & 19.265 & $<0.001$ & 1.881 & 0.176 \\
\hline Anger-hostility & $1.4 \pm 0.4^{\#}$ & $0.1 \pm 0.1^{*}$ & $0.7 \pm 0.2$ & $0.2 \pm 0.1$ & 1.958 & 0.168 & 12.418 & $<0.001$ & 3.104 & 0.084 \\
\hline Vigor & $8.3 \pm 0.8$ & $10.2 \pm 1.0^{*}$ & $9.7 \pm 0.8$ & $12.6 \pm 0.9^{*}$ & 3.047 & 0.087 & 19.049 & $<0.001$ & 0.857 & 0.359 \\
\hline Fatigue & $2.7 \pm 0.7$ & $1.2 \pm 0.4^{*}$ & $2.2 \pm 0.7$ & $0.6 \pm 0.2^{*}$ & 0.898 & 0.348 & 9.447 & 0.003 & 0.005 & 0.942 \\
\hline Confusion & $4.9 \pm 0.5$ & $3.0 \pm 0.3^{*}$ & $4.9 \pm 0.6$ & $2.8 \pm 0.3^{*}$ & 0.077 & 0.782 & 30.282 & $<0.001$ & 0.130 & 0.720 \\
\hline
\end{tabular}

Values are shown as the mean \pm SEM. $* \mathrm{p}<0.05$ vs. pre-forest-walking values within each group. ${ }^{*} \mathrm{p}<0.05$ vs. nonresponder group within pre-forest-walking values

indicated that forest walking in itself may improve health; however, greater-walking-related AEE might be required to accentuate physiological benefits.

Previous studies have demonstrated that the decreases in SBP and/or DBP following forest walking are significantly greater than the SBP and/or DBP decreases observed after walking in urban areas ${ }^{2,4)}$. Forest walking-induced reductions in $\mathrm{BP}$ can be explained by changes in sympathetic nerve activity. A previous study showed that sympathetic nerve activity, which was assessed through direct measurements of sympathetic nerve activity using microneurography, i.e., muscle sympathetic nerve activity, may help regulate $\mathrm{BP}^{18)}$. In addition, indirect assessments of sympathetic nerve activity through heart rate variability (HRV) were associated with BP control in prehypertensive humans ${ }^{19}$ ). Although the precise mechanisms and interactions between changes in BP and HRV are still unclear in this study, there is a possibility that forest environments may increase parasympathetic nerve activity, resulting in BP decreases. Horiuchi et al. ${ }^{7)}$ recently found that both SBP and DBP were reduced in elderly people, but not in younger people, after forest walking. However, their study could not discriminate between the effects of walking and forest environments $\mathrm{per} \mathrm{se} \mathrm{s}^{7}$. Therefore, we should be cautious in interpreting results regarding the impact of forest walking on BP changes. It has been suggested that a higher intensity and longer duration provoke a greater magnitude, and longer duration of, BP reductions after a single bout of exercise ${ }^{8-10)}$. In addition, one interesting study revealed that $\mathrm{PEH}$ was similar following a short period of high- intensity exercise and a longer period of moderateintensity exercise that were matched for total work rate, suggesting that total energy expenditure may affect $\mathrm{PEH}^{20)}$. These previous studies may partially support our results showing that enhanced AEE led to a greater MAP reduction in forest-walking Rs. Another potential explanation may be related to different initial values in BP between groups. In this study, MAP was calculated as $[(\mathrm{SBP}-\mathrm{DBP}) / 3+\mathrm{DBP}]$, indicating that DBP values may be related to MAP values. Indeed, the initial DBP values before forest walking in the $\mathrm{R}$ group were significantly higher than those in the NR group. Moreover, the initial MAP values in the R group were also higher in the NRs with no statistical differences between groups. Since it has been demonstrated that people with higher resting BP values may show greater hypotension after exercise ${ }^{21)}$, even slight differences in MAP values between groups may have caused greater reductions in the $\mathrm{R}$ group. However, the lack of correlation between AEE and MAP in NRs still cannot be fully explained. Although we can only speculate, the AEE in NRs may not be sufficient to reduce MAP; it is also possible that less variance in MAP resulted in no visible relationship.

It has been reported that sAMY levels in individuals exposed to a forest environment were lower than those in individuals in urban environments when both sets of individuals walked in and observed the surrounding landscape ${ }^{5)}$. Similarly, a recent field study also revealed that, in a very natural environment, sAMY was significantly lower than in a built-up setting ${ }^{22}$. Our results failed to reveal a marked 
improvement of these stress markers in both groups. However, it should be noted that these previous studies compared sAMY between urban and forest environments, and found a significant difference between the two conditions. Therefore, they did not investigate whether the forest environment per se reduced salivary stress markers. In addition, Beil and Hanes ${ }^{22)}$ found that sAMY increased slightly, even in a very natural environment, despite a significant decrease in the feeling of stress. These findings indicate that our results, which showed no difference between before and after forestwalking, may not be unnatural.

Previous field studies have found that the subscales of the POMS are improved through forest viewing and walking ${ }^{1-3,7)}$. These results appear to be consistent with our findings, in that the forest environment, including walking in the forest environments, improved the participants' POMS subscale scores, and it is unlikely that differential EE and/ or MAP changes are related to individuals' POMS scores. However, one different result was the significant improvement observed in the A-H subscale of the POMS in the R group, with it remaining unchanged in the NR group. As the pre- forest-walking values of A-H were significantly lower in the NR group, which showed no A-H feelings, it might be reasonable to expect no further improvement in this subscale. Another possibility is the relationship between these negative feelings and risk of cardiovascular disease. Previous studies have found that feelings of great anger or hostility are closely related to hypertension ${ }^{23)}$. Moreover, psychosocial stress has been implicated in the pathogenesis of essential hypertension ${ }^{24)}$, and elevated stress has also been associated with an increased risk of atherosclerosis ${ }^{25}$ ) and acute cardiovascular events ${ }^{26)}$. The mechanisms underlying these links are complex, because it should be considered that effect of exercise per se on improvements of the POMS in both groups. However, it was reported that a health promotion program consisting of easy and simple exercise improved psychological attitudes including a subscale of the POMS, indicating that consecutive exercise per se may be useful for improvement of psychological stress ${ }^{27}$. Thus, although future studies are warranted, our results may indicate that forest walking can improve the POMS, irrespective of MAP changes, suggesting that forest walking may be a potential strategy to reduce psychological stress in middle-aged and elderly people.

Several limitations should be considered in interpreting the results of this study. First, we did not perform a control study, e.g., a study of city walking. Indeed, previous studies have examined effects of forest walking and bathing on BP compared with city walking, and their results showed a greater reduction in BP with forest walking than with city walking ${ }^{2-4)}$. However, it is very difficult to control energy expenditure under different conditions, i.e., the forest and city, because numerous factors, such as walking speed, gradients, and environmental conditions, can change the activity energy expenditure. Accordingly, we did not want to compel subjects to control their walking speed, etc, because it is likely that walking at a comfortable pace is a more important issue in evaluating effects of forest walking. More importantly, our main aim was to examine effects of energy expenditure on BP during forest walking; furthermore, our study attempted to suggest a way to walk, even in forest environments for human health. In this regard, our results clearly demonstrated that greater AEE may have more positive effects, but mental health assessed by the POMS was not affected by differences in AEE. Although future studies are required to elucidate the underlying mechanisms of forest walking for human heath, the current results can be applied to people who would like to try forest walking and can be used to propose an appropriate walking method under forest conditions. Second, our participants were both males and females, some participants were taking medications, and the menstrual cycle in middle-aged women was different between groups. It could not be completely ruled out that these variables has possible effects; however, our statistical analysis clearly demonstrated no differences between the two groups according to gender, medication, and menstrual cycle status. Also only one study has reported that betablocker treatment influenced resting BP levels; however, the exercise-induced reduction in BP was unaffected compared with a placebo ${ }^{28)}$. In addition, a previous study found that gender difference and menstrual cycle ${ }^{29)}$ have little effect on $\mathrm{PEH}$. Moreover, the numbers of middle-aged women who had a normal menstrual cycle were relatively small in each group in the present study ( $\mathrm{n}=2$ in the $\mathrm{R}$ group and $\mathrm{n}=3$ in the NR group). Thus, it is unlikely that our primary conclusions were affected by these influences.

In summary, greater EE during forest walking was associated with a greater reduction in MAP, but greater EE did not strongly affect changes in the POMS. These results suggest that greater-walking-related EE might be required to accentuate physiological beneficial effects on health in middle-aged and aged people, in particular, those who are prehypertensive and hypertensive. Furthermore, the forest environment per se can attenuate psychological stress irrespective of AEE during walking. With regard to the strategy of forest walking, our results may, therefore, provide useful information for prehypertensive and hypertensive people who can perform a kind of brisk walking and/or people with mental stress who cannot.

\section{REFERENCES}

1) Horiuchi M, Endo J, Takayama N, et al.: Impact of viewing vs. not viewing a real forest on physiological and psychological responses in the same setting. Int J Environ Res Public Health, 2014, 11: 10883-10901. [Medline] [CrossRef]

2) Mao GX, Cao YB, Lan XG, et al.: Therapeutic effect of forest bathing on human hypertension in the elderly. J Cardiol, 2012, 60: 495-502. [Medline] [CrossRef]

3) Park BJ, Tsunetsugu Y, Kasetani $T$, et al.: The physiological effects of Shinrin-yoku (taking in the forest atmosphere or forest bathing): evidence from field experiments in 24 forests across Japan. Environ Health Prev Med, 2010, 15: 18-26. [Medline] [CrossRef]

4) Tsunetsugu Y, Park BJ, Ishii H, et al.: Physiological effects of Shinrin-yoku (taking in the atmosphere of the forest) in an old-growth broadleaf forest in Yamagata Prefecture, Japan. J Physiol Anthropol, 2007, 26: 135-142. [Medline] [CrossRef]

5) Yamaguchi M, Deguchi M, Miyazaki Y: The effects of exercise in forest and urban environments on sympathetic nervous activity of normal young adults. J Int Med Res, 2006, 34: 152-159. [Medline] [CrossRef]

6) Fuks K, Moebus S, Hertel S, et al. Heinz Nixdorf Recall Study Investigative Group: Long-term urban particulate air pollution, traffic noise, and arterial blood pressure. Environ Health Perspect, 2011, 119: 1706-1711. [Medline] [CrossRef]

7) Horiuchi M, Endo J, Akatsuka S, et al.: Influence of forest walking on 
blood pressure, profile of mood states and stress markers from the viewpoint of aging. J Aging Gerontol, 2013, 1: 9-17.

8) Forjaz CL, Cardoso CG Jr, Rezk CC, et al.: Postexercise hypotension and hemodynamics: the role of exercise intensity. J Sports Med Phys Fitness, 2004, 44: 54-62. [Medline]

9) Guidry MA, Blanchard BE, Thompson PD, et al.: The influence of short and long duration on the blood pressure response to an acute bout of dynamic exercise. Am Heart J, 2006, 151: 1322.e5-1322.e12. [Medline] [CrossRef]

10) Pescatello LS, Guidry MA, Blanchard BE, et al.: Exercise intensity alters postexercise hypotension. J Hypertens, 2004, 22: 1881-1888. [Medline] [CrossRef]

11) Karoline de Morais P, Sales MM, Alves de Almeida J, et al.: Effects of aerobic exercise intensity on 24-h ambulatory blood pressure in individuals with type 2 diabetes and prehypertension. J Phys Ther Sci, 2015, 27 51-56. [Medline] [CrossRef]

12) Kumahara $\mathrm{H}$, Schutz $\mathrm{Y}$, Ayabe $\mathrm{M}$, et al.: The use of uniaxial accelerometry for the assessment of physical-activity-related energy expenditure: a validation study against whole-body indirect calorimetry. Br J Nutr, 2004, 91 235-243. [Medline] [CrossRef]

13) Kai S, Koga M: Autonomic nerve responses in a psychologiocal stress task and subsequent slow breathing. J Phys Ther Sci, 2012, 24: 257-259. [CrossRef]

14) Yamaguchi M, Deguchi M, Wakasugi J, et al.: Hand-held monitor of sympathetic nervous system using salivary amylase activity and its validation by driver fatigue assessment. Biosens Bioelectron, 2006, 21: 1007-1014. [Medline] [CrossRef]

15) McNair DM, Lorr M: An analysis of mood in neurotics. J Abnorm Psychol, 1964, 69: 620-627. [Medline] [CrossRef]

16) Yokoyama K, Araki S, Kawakami N, et al.: [Production of the Japanese edition of profile of mood states (POMS): assessment of reliability and validity]. Nippon Koshu Eisei Zasshi, 1990, 37: 913-918. [Medline]

17) Guidelines for the Management of Hypertension: 2014: The Japanese Society of Hypertension, 2014

18) Narkiewicz K, Winnicki M, Schroeder K, et al.: Relationship between muscle sympathetic nerve activity and diurnal blood pressure profile. Hypertension, 2002, 39: 168-172. [Medline] [CrossRef]

19) Pal GK, Adithan C, Amudharaj D, et al.: Assessment of sympathovagal imbalance by spectral analysis of heart rate variability in prehypertensive and hypertensive patients in Indian population. Clin Exp Hypertens, 2011, 33: 478-483. [Medline] [CrossRef]

20) Jones H, George K, Edwards B, et al.: Is the magnitude of acute post-exercise hypotension mediated by exercise intensity or total work done? Eur J Appl Physiol, 2007, 102: 33-40. [Medline] [CrossRef]

21) Forjaz CL, Tinucci T, Ortega KC, et al.: Factors affecting post-exercise hypotension in normotensive and hypertensive humans. Blood Press Monit, 2000, 5: 255-262. [Medline] [CrossRef]

22) Beil K, Hanes D: The influence of urban natural and built environments on physiological and psychological measures of stress - a pilot study. Int J Environ Res Public Health, 2013, 10: 1250-1267. [Medline] [CrossRef]

23) Compare A, Grossi E, Buscema M, et al.: Combining personality traits with traditional risk factors for coronary stenosis: an artificial neural networks solution in patients with computed tomography detected coronary artery disease. Cardiovasc Psychiatry Neurol, 2013, 2013: 814967. [Medline] [CrossRef]

24) Esler M, Eikelis N, Schlaich M, et al.: Chronic mental stress is a cause of essential hypertension: presence of biological markers of stress. Clin Exp Pharmacol Physiol, 2008, 35: 498-502. [Medline] [CrossRef]

25) Rozanski A, Blumenthal JA, Kaplan J: Impact of psychological factors on the pathogenesis of cardiovascular disease and implications for therapy. Circulation, 1999, 99: 2192-2217. [Medline] [CrossRef]

26) Rosengren A, Hawken S, Ounpuu S, et al. INTERHEART investigators Association of psychosocial risk factors with risk of acute myocardial infarction in 11119 cases and 13648 controls from 52 countries (the INTERHEART study): case-control study. Lancet, 2004, 364: 953-962. [Medline] [CrossRef]

27) Nakagawa K, Inomata N, Nakazawa R, et al.: The effect of a health promotion program consisting of easy and simple exercises for communitiy living elderly people. J Phys Ther Sci, 2007, 19: 235-242. [CrossRef]

28) Wilcox RG, Bennett T, Macdonald IA, et al.: Post-exercise hypotension: the effects of epanolol or atenolol on some hormonal and cardiovascular variables in hypertensive men. Br J Clin Pharmacol, 1987, 24: 151-162. [Medline] [CrossRef]

29) Lynn BM, McCord JL, Halliwill JR: Effects of the menstrual cycle and sex on postexercise hemodynamics. Am J Physiol Regul Integr Comp Physiol, 2007, 292: R1260-R1270. [Medline] [CrossRef] 